\title{
PERCEPÇÃO DOS PAIS DE CRIANÇAS COM IMPLANTE COCLEAR USUÁRIAS DA LIINGUA BRASILEIRA DE SINAIS
}

\author{
PARENTS PERCEPTION OF CHILDREN WITH COCHLEAR \\ IMPLANT USERS OF BRAZILIAN SIGN LANGUAGE
}

\section{Lauriene Franchi Dionisio', Maria Cecília Marconi Pinheiro Lima²}

\section{RESUMO}

Objetivo: O objetivo do estudo foi conhecer a percepção dos pais em relação ao implante coclear utilizado por seus filhos e o processo de aquisição da Língua Brasileira de Sinais (LIBRAS). Os participantes foram familiares de crianças usuárias de implante coclear atendidas em Instituição pública do Estado de São Paulo. Pesquisa do tipo transversal, análise qualitativa. Aplicou-se um roteiro de entrevista semiestruturado, sendo as entrevistas gravadas e transcritas para categorização e análise dos dados, por meio da análise conteúdo. Os familiares relataram que estão satisfeitos com a escolha pelo implante coclear; o processo de aprendizagem da LIBRAS foi natural e benéfico e relataram expectativas positivas sobre o futuro das crianças. Concluiu-se que os pais veem a escolha pelo implante coclear como algo positivo, devido ao desenvolvimento da comunicação das crianças e que a LIBRAS contribuiu para o processo de desenvolvimento de linguagem das crianças.

Descritores: Implante Coclear; Linguagem de Sinais; Criança; Surdez; Perda Auditiva.

\begin{abstract}
Objective: The aim of this study was to know the parents perception about their children with cochlear implant and Brazilian Sign Language (LIBRAS). Participants were parents of children with cochlear implants attended in a public institution of the State of São Paulo. Cross sectional research with qualitative analysis. We applied a semi-structured interview, which were recorded and transcribed for categorizing and analyzing data, by analyzing content. The families were satisfied with the choice of the cochlear implant; the language learning process was natural and beneficial and for their future, relatives reported positive expectations for the children. Thus, it was concluded that parents see the choice of cochlear implant as something positive due to the communication development of children and that LIBRAS contributed to the language development process of children.
\end{abstract}

Descriptors: Cochlear Implantation; Sign Language; Child; Deafness; Hearing Loss.
${ }^{1}$ Fonoaudióloga pela Universidade Estadual de Campinas (UNICAMP), Campinas, SP, Brasil.

2 Fonoaudióloga pela Pontifícia Universidade Católica de Campinas (PUCC), Campinas, SP, Brasil. 


\section{Introdução}

O implante coclear é definido como um "dispositivo eletrônico de alta tecnologia, que estimula eletricamente as fibras nervosas remanescentes, permitindo a transmissão do sinal elétrico ao nervo auditivo, para que seja codificado pelo córtex cerebral"1. Esse dispositivo veio como alternativa para os indivíduos que tem perda auditiva de grau severo a profundo e que 0 aparelho de amplificação sonora não apresenta os resultados satisfatórios em discriminação de palavras e sentenças².

É fundamental ressaltar a importância da avaliação fonoaudiológica nesse processo, pois a família do paciente que receberá o implante deve ter conhecimento do funcionamento do implante, benefícios e limitações. Além disso, ressaltase a importância da avaliação pelo profissional da área de assistência social sobre as condições socioeconômicas da família para investimentos em manutenção e cuidados do implante coclear e da avaliação psicológica, a fim de se trabalhar as expectativas reais da família e a motivação do paciente para o longo caminho da reabilitação auditiva ${ }^{3}$.

De modo geral, os defensores do implante coclear acreditam que a abordagem oralista deve ser utilizada com o sujeito com deficiência auditiva, ou seja, o sujeito deve adquirir a língua oral apenas por meio da reabilitação da audição e estratégias como a leitura orofacial. Por outro lado, há estudos que mostram o desenvolvimento efetivo da área cognitiva e da linguagem quando há o aprendizado da língua de sinais pelo indivíduo surdo no mesmo período em que ocorre a aquisição da língua oral na criança ouvinte. A não aquisição de uma língua (oral ou de sinais) durante os primeiros anos de vida do sujeito pode causar prejuízos psicossociais de isolamento e frustração por falta de habilidades linguísticas ${ }^{4}$. A privação de uma língua pode trazer prejuízos pela própria diminuição de experiência linguística. Isso quer dizer que após os cinco primeiros anos de vida a plasticidade do cérebro diminui tornando mais difícil a aquisição de uma primeira língua ${ }^{4}$.

No Brasil, a Lei n 10.436 de 24 de abril de 2002 traz a Língua Brasileira de Sinais (LIBRAS) como língua de fato, com sistema linguístico de natureza visuo-motora, com estrutura gramatical própria e capaz de transmitir ideias ${ }^{5}$.

Na literatura, é apontada a diferença de identidades em relação à pessoa com deficiência auditiva e a pessoa surda6. É importante levar em conta o sujeito que se identifica como pessoa com deficiência auditiva (visão de ter uma doença, uma defasagem e, por isso, o foco em recursos para reestabelecer audição e adquirir a Língua Portuguesa como primeira língua - L1) e do sujeito que se identifica como surdo (se apropria de cultura própria e se vê com uma diferença linguística em que a L1 é a LIBRAS). Sendo assim, é possível refletir sobre a relevância da convivência com os semelhantes para a aquisição da língua assim como da identidade ${ }^{6}$.

É de simples compreensão que a língua oral é mais complexa de ser adquirida pela criança surda nos primeiros anos de vida. Desse modo, o surdo terá facilidade em aprender uma língua visual como primeira língua tendo desenvolvimento cognitivo suficiente para aprender outras línguas, sendo elas orais ou não. É necessário refletir que a criança, enquanto não descoberta a surdez e/ou durante o processo de decisão pelo implante coclear ou pelos aparelhos de amplificação sonora ou até mesmo levando em conta a localização e recursos disponíveis para essa família, fica com um intervalo de tempo importante durante o desenvolvimento da linguagem, ou seja, o período em que deveria adquirir uma língua fica prejudicado e após os cinco primeiros anos de vida - como citado anteriormente - o sujeito tem dificuldade de adquirir qualquer língua e fazer uso dela de maneira efetiva.

Dias e Lourenço (2016), em um estudo recente, trazem que crianças que fizeram a cirurgia de implante coclear tardiamente e que tiveram apoio da língua de sinais desenvolveram oralidade e competências linguísticas tão bem quanto crianças que implantaram precocemente e não tiveram a língua de sinais ${ }^{7}$.

O desejo da família ouvinte de querer um filho ouvinte pode trazer situações conflitantes durante a descoberta da surdez da criança. Vindo de uma família ouvinte, é de se esperar expectativa maior em relação à fala. Porém, à medida que a interação vai acontecendo a modalidade usada será determinada, ou seja, pela língua oral ou gestual ${ }^{8}$.

Assim, o objetivo do estudo foi conhecer a percepção dos pais em relação ao implante coclear utilizado por seus filhos e o processo de aquisição de LIBRAS.

\section{Metodologia}

Pesquisa do tipo transversal, com abordagem qualitativa. A técnica de análise utilizada foi pela análise de conteúdo, segundo Bardin ${ }^{12}$. O desenho deste estudo trabalha com o universo de significados, dos motivos, atitudes, pois o indivíduo se diferencia não só por agir, mas por pensar sobre o que realiza e por interpretar ações a partir da realidade vivida e 
compartilhada ${ }^{9}$. A pesquisa qualitativa se preocupa com o contexto histórico, a cultura, a política e ideologias e não pode ser contida apenas em dados numéricos e estatísticos, considerando que o objeto de estudo é subjetivo, contraditório e permanece em constante transformação $0^{10}$.

A pesquisa foi realizada em um Centro de Estudos de uma instituição pública no estado de São Paulo que atende pessoas surdas de todas as faixas etárias nas áreas de pedagogia, fonoaudiologia e linguística. Essa instituição foi escolhida, pois, a pesquisadora fazia parte do programa de aprimoramento que era oferecido nesse local.

Os sujeitos da pesquisa consistiram em cinco familiares (quatro mães e um pai) de crianças que fizeram implante coclear há mais de um ano, atendidas em um Programa intitulado Desenvolvimento Infantil, Linguagem e Surdez do Centro descrito acima. Foram coletados dados relacionados a grau de parentesco, idade, naturalidade e escolaridade.

Foram inclusos na pesquisa todos os familiares de crianças que fizeram parte do Programa Desenvolvimento Infantil, Linguagem e Surdez, usuários de implante coclear, que concordaram e assinaram o Termo de Consentimento Livre e Esclarecido no período de outubro e novembro de 2015. Foram excluídos da pesquisa os familiares das crianças que não estavam inseridas no Programa de Desenvolvimento Infantil, Linguagem e Surdez e usuárias de próteses auditivas.

O procedimento para coleta de dados consistiu na aplicação de um roteiro de entrevista semiestruturado. As entrevistas foram compostas por perguntas-guias para que o entrevistado se sentisse a vontade para relatar o que sentia em relação aos assuntos colocados e, dessa forma, possa ter maior explanação das histórias de vida e ao mesmo tempo o entrevistador guiando as questões para alcançar os objetivos. As perguntas-guias abordaram o processo da descoberta da surdez, informações e orientações recebidas sobre o implante coclear, aspectos sobre a Língua Brasileira de Sinais e expectativas em relação ao futuro das crianças. O roteiro utilizado continha as seguintes perguntas: 1. Quem percebeu a dificuldade de escutar da criança? 2. Como foi dado o diagnóstico? 3. Quais as orientações recebidas sobre o IC? 4. Está satisfeito com essa escolha? Porque? 5. Alguém explicitou os valores de manutenção do IC? 6. Como a criança se comunica agora? 7. Como você se sentiu quando a LIBRAS foi introduzida? 8. Teve alguma diferença na comunicação da criança depois da introdução da LIBRAS? Se sim, quais? 9. Quais as expectativas em relação ao futuro da criança?

Inicialmente, o roteiro semiestruturado foi aplicado a um sujeito a fim de realizar um estudo exploratório para possíveis modificações, por exemplo, adicionar questionamentos relevantes, tornar as perguntas mais claras. 0 sujeito se encontrava dentro dos critérios de inclusão (relatados anteriormente). Após o estudo exploratório e as devidas modificações, o roteiro semiestruturado foi aplicado aos sujeitos em forma de entrevista por um único/mesmo pesquisador. As entrevistas foram gravadas, transcritas na íntegra e os dados foram analisados pelo mesmo pesquisador que aplicou as entrevistas. Data e local das entrevistas foram marcados de acordo com a disponibilidade dos familiares. Para garantia da privacidade e sigilo dos sujeitos todos foram numerados para discorrer sobre os resultados e discussão.

Considerando que a pesquisa qualitativa lida com sujeitos e sua subjetividade, é possível compreender que 0 objeto da pesquisa se constituiu e é constituído na e pela linguagem. Desse modo, quando se quer compreender além dos significados que os dados apresentam é necessário se utilizar da análise de conteúdo, ou seja, é preciso descobrir, ir além das aparências ${ }^{11}$.

Os dados qualitativos foram agrupados de acordo com as categorias selecionadas, procedendo-se à análise do conteúdo que segundo Bardin ${ }^{12}$, é um "conjunto de técnicas de análise das comunicações visando obter, por procedimentos sistemáticos e objetivos de descrição do conteúdo das mensagens, indicadores (quantitativos ou não) que permitem a inferência de conhecimentos relativos às condições de produção/recepção (variáveis inferidas) destas mensagens", ou seja, é através da análise de conteúdo que é possível ir além das aparências do que está sendo comunicado.

Foram elaboradas quatro categorias: a) percepção sobre o processo da descoberta da surdez; b) informações e orientações recebidas sobre o implante coclear; c) percepção sobre LIBRAS; d) expectativas em relação ao futuro da criança.

A categorização é uma operação classificatória de informações e seguida por um reagrupamento, que tem como objetivo fornecer, por adensamento, uma representação simplificada dos dados em bruto ${ }^{11}$. Sendo as categorias classes que reúnem elementos com características em comum, as categorias foram estabelecidas no processo de inventário - em que os elementos são isolados - e a classificação - em que os elementos são repartidos e impostos em certa organização ${ }^{12}$.

Essa pesquisa foi aprovada pelo Comitê de Ética em Pesquisa da Instituição, sob o número do CAAE: 48181115.5.0000.5404, em 03/09/2015. 


\section{Resultados e Discussão}

A média de idade dessas crianças foi de 8,8 anos de idade e o grupo foi composto por três crianças com surdez adquirida, uma criança com surdez congênita e uma criança sem diagnóstico concluído. Todas as crianças cursavam 0 ensino fundamental e apenas duas delas fizeram a mesma série mais de uma vez. As hipóteses diagnósticas variaram entre rubéola congênita, medicamento ototóxico, prematuridade, meningite e diagnóstico não fechado (Tabela 1).

Tabela 1 - Caracterização das crianças quanto à idade, escolaridade, hipótese diagnóstica e tempo de uso do implante coclear

\begin{tabular}{c|c|c|c|c}
\hline Criança & Idade & $\begin{array}{c}\text { Escolaridade/ } \\
\text { ensino fundamental }\end{array}$ & $\begin{array}{c}\text { Hipótese } \\
\text { Diagnóstica }\end{array}$ & $\begin{array}{c}\text { Tempo de uso do } \\
\text { Implante Coclear }\end{array}$ \\
\hline Criança 1 & 10 anos & $4^{\circ}$ ano & Rubéola Congênita & Unilateral: 5 anos \\
\hline Criança 2 & 7 anos & $2^{\circ}$ ano & $\begin{array}{c}\text { Medicamento } \\
\text { ototóxico }\end{array}$ & OD: 2 anos \\
\hline Criança 3 & 6 anos & $1^{\circ}$ ano & $\begin{array}{c}\text { Sem diagnóstico } \\
\text { definido }\end{array}$ & Unilateral: 3 anos \\
\hline Criança 4 & 9 anos & $3^{\circ}$ ano & Meningite & Unilateral: 6 anos \\
\hline Criança 5 & 12 anos & $4^{\circ}$ ano & $\begin{array}{c}\text { Prematuridade e } \\
\text { presença em UTI }\end{array}$ & Unilateral: 6 anos \\
\hline
\end{tabular}

Legenda: OD-Orelha Direita, OE-Orelha Esquerda, UTI-Unidade de Terapia Intensiva

Foram entrevistados cinco familiares de crianças usuárias de implante coclear, sendo quatro mães e um pai. As crianças eram atendidas no Centro de Estudos e as entrevistas foram realizadas enquanto as crianças eram atendidas.

A faixa etária dos familiares permaneceu entre 20 e 40 anos. A maioria deles cursou o ensino médio completo. A seguir, a tabela de caracterização dos familiares.

Tabela 2 - Caracterização dos familiares quanto ao grau de parentesco, idade, naturalidade e escolaridade

\begin{tabular}{c|c|c|c|c}
\hline Familiar & Grau de parentesco & Idade & Naturalidade & Escolaridade \\
\hline Sujeito 1 & Mãe & 32 anos & Hortolândia - SP* & $\begin{array}{c}\text { Ensino Médio } \\
\text { Completo }\end{array}$ \\
\hline Sujeito 2 & Mãe & 40 anos & Campinas - SP* & $\begin{array}{c}\text { Ensino Fundamental } \\
\text { Incompleto }\end{array}$ \\
\hline Sujeito 3 & Mãe & 26 anos & Bueno Brandão - MG** & $\begin{array}{c}\text { Ensino Médio } \\
\text { Completo }\end{array}$ \\
\hline Sujeito 4 & Pai & 35 anos & Monte Mor - SP* & $\begin{array}{c}\text { Ensino Médio } \\
\text { Completo }\end{array}$ \\
\hline Sujeito 5 & Mãe & 34 anos & Hortolândia - SP* & $\begin{array}{c}\text { Ensino Médio } \\
\text { Completo }\end{array}$ \\
\hline
\end{tabular}

*SP- São Paulo, ${ }^{* *} \mathrm{MG}$ - Minas Gerais 
Para análise dos resultados, os dados foram divididos em quatro categorias, descritas a seguir:

\section{Percepções sobre o processo da descoberta da surdez}

Para muitas famílias, o nascimento de uma criança pode significar momentos de alegria, felicidade e união entre os membros da família. Porém, quando nasce uma criança com alguma deficiência pode significar momentos de lágrimas, tristeza, medo, confusão e desespero ${ }^{13}$. No estudo, foi possível observar relatos dos familiares sobre os sentimentos negativos durante o momento do diagnóstico.

O sujeito 1, por exemplo, relatou que no momento em que foi dado o diagnóstico da perda auditiva pelo médico, não queria aceitar o que estava sendo dito:

"No momento eu não queria aceitar. Eu falei não, não." (Sujeito1)

Um estudo de Vieira, Bevilacqua, Ferreira e Dupas mostrou o aparecimento de sentimentos negativos na família como revolta, medo, frustração, não aceitação, susto, chateação, desespero, angústia, confusão, tristeza, culpa, contrariedade, preconceito, uma sensação de vazio interior, choque, vergonha, depressão e ansiedade ${ }^{14}$. Na pesquisa em questão, mesmo os cinco familiares não sendo questionados diretamente sobre os sentimentos que o momento do diagnóstico provocou, foi possível observar nos relatos dos pais a negação no início do processo de habilitação/ reabilitação auditiva da criança.

Quatro familiares relataram que foi alguém da família que percebeu que a criança tinha dificuldades de ouvir. Todas as crianças tinham dois anos de idade ou menos quando alguém desconfiou da perda auditiva. Porém, todos os familiares indicaram que o diagnóstico e/ou a intervenção foram tardias, sendo que as crianças foram encaminhadas para o implante coclear e acompanhamento com profissionais da saúde pelo menos um ano depois da descoberta da surdez. Ao pensar em desenvolvimento de linguagem e fala da criança podemos destacar a importância da intervenção precoce. A identificação tardia da deficiência auditiva pode acarretar em muitas dificuldades (de linguagem, escolares, sociais) para a criança, o que a deixa distante de um desempenho como a de uma criança ouvinte ${ }^{14}$.

Três familiares relataram que consultaram vários profissionais que disseram que o filho ouvia normalmente. Um desses familiares relatou que o pediatra encaminhou o filho para o neurologista, pois, desconfiou que a criança tivesse autismo. 0 neurologista fez alguns testes auditivos e encaminhou para o otorrinolaringologista para avaliação e conduta adequadas.

Portanto, pode-se observar o aparecimento de sentimentos negativos em comum entre os familiares, sendo possível pressupor a importância do acompanhamento dos familiares por profissionais da saúde quanto ao processo de descoberta do diagnóstico, pois, muitos são os sentimentos que precisam ser trabalhados. É necessário também destacar a relevância do diagnóstico e intervenção precoce para o desenvolvimento da criança.

\section{Informações e orientações recebidas sobre o implante coclear}

Em relação ao implante coclear, os cinco familiares relataram que receberam orientações, sendo que cuidados em relação à limpeza e manutenção foram os mais citados.

É possível observar em protocolos médicos e audiológicos fator importante quando se trata da preparação da família e do candidato ao implante coclear, a questão das informações e orientações sobre o funcionamento do aparelho, os benefícios e limites que ele pode trazer².

Todos os familiares relataram estar satisfeitos com a escolha pelo implante coclear. Encontrou-se na literatura 0 estudo que mostrou que as crianças que utilizavam o implante coclear por mais de 4 anos em idade escolar (as crianças da pesquisa apresentaram faixa etária de 4 a 6 anos de idade), apresentaram sucesso em demandas sociais e escolares, além dos benefícios de fala e linguagem ${ }^{15}$. Ou seja, os pais apresentaram-se satisfeitos com a escolha pelo implante coclear e com os resultados que observaram na vida cotidiana da criança.

Foi possível observar também discursos contraditórios da maioria dos familiares (quatro) sobre essa mesma questão. Durante o discurso apareceram falas sobre o implante coclear estar quebrado e sem previsão para conserto, três crianças estavam sem implante coclear, orçamentos que não foram possíveis pagar e também apareceu a LIBRAS como protagonista na questão do implante coclear. Sobre o investimento relacionado à quebra de peças do implante 
coclear, três familiares disseram que sabiam sobre os preços. Porém, dois familiares disseram que não foram alertados sobre os custos. Um desses familiares relatou que descobriu o valor apenas agora que o implante está quebrado.

"Eu to satisfeita com a escolha pelo implante, só que agora que quebrou, faz 2 anos que quebrou a gente ta com protocolo na prefeitura pra poder arrumar esse aparelho. Agora parece que vai sair. Porque o aparelhinho dele quebrou e ficou quase, ficou em $R \$ 7.385,00$, o conserto e a gente não tem esse dinheiro. Aí, agora a gente tentou com processo na prefeitura e aí se eles negativar a gente vai com aquele mandato de segurança." (Sujeito 1)

Conclui-se que os familiares ficaram satisfeitos em relação à escolha pelo implante coclear já que os avanços no desenvolvimento das crianças foram observados. Também demonstraram satisfação ao receber informações e orientações gerais de uso. Importante refletir sobre a questão dos custos do implante coclear.

\section{Percepções sobre a Língua Brasileira de Sinais}

Ao serem questionadas sobre a introdução da LIBRAS, quatro familiares relataram que o processo de aprendizagem da língua foi natural e benéfico para as crianças. Uma das mães relatou resistência no início, porém, foi observando avanços na comunicação da filha e aceitou que a mesma adquirisse a língua de sinais. Sendo assim, três familiares disseram que a principal forma de comunicação é por meio da língua de sinais e dois familiares disseram que as crianças se comunicam tanto por língua portuguesa quanto por língua de sinais, de forma que quando a criança não sabe oralizar determinado léxico utiliza sinal.

Tem-se ainda - de forma unânime - a diferença que a língua de sinais fez na linguagem das crianças. Todos os pais afirmaram que a criança está mais comunicativa e compreensível.

Nessa fala, fica clara a satisfação mesmo com a quebra do aparelho e com a dificuldade que será pagar o conserto do implante coclear. Alguns autore ${ }^{16}$ trazem como condições fundamentais para o desenvolvimento do potencial auditivo do indivíduo a adaptação ao implante coclear juntamente com o apoio e disponibilidade da família e profissionais habilitados para o trabalho. Neste momento, se faz necessária a reflexão sobre o que acontecerá com a audição em si, o desenvolvimento da linguagem e a evolução da criança que está com implante coclear quebrado, pois, a plasticidade cerebral durante a infância muda e quando a criança não adquire a primeira língua no tempo ideal não existe fluência dessa língua 4 .

"To. To bem satisfeita. Assim, sabe, eu sei que a Libras seria uma língua, é uma língua normal pra... agora pra mim, é uma língua normal, né?. Mas, assim, ouvir as palavras da minha filha: mamãe, papai é uma coisa muito boa. Pra vários otorrinos que falou que minha filha não ia falar nada e minha filha ta falando bastante coisinha já, é muito bom." (Sujeito 2)

"To muito, muito[satisfeita]. Na verdade a gente optou pela Libras porque ele tava demorando muito pra falar. Porque ele tava fazendo fonoaudióloga na minha cidade. Mas, estava demorando muito pra aprender a falar. Então já ta na fase de... já ta na escola, tudo e eu e meu marido optamos pelo Libras porque preciso de uma linguagem, né? Não tem como viver o resto da vida com gesto caseiro. Mas daí através da Libras ele começou a falar. Ainda ta falando pouco é lógico mas já ta num bom começo." (Sujeito 3)

Nos discursos dos sujeitos 2 e 3, é possível observar o significado que a LIBRAS teve na vida das crianças. Houve mudanças positivas em relação à linguagem e à própria fala. Na literatura, alguns autores ${ }^{4}$, trazem como prejuízo a falta de uma primeira língua para o indivíduo. A privação linguística pode acarretar em prejuízos cognitivos, psicossociais como isolamento e frustação pela própria diminuição de experiência linguística. Desse modo, é de fácil compreensão a aceitação dos familiares pela língua de sinais (língua visuo-motora), portanto, mais acessível que língua oral- para os filhos surdos.

Desde 2002, o Brasil reconhece a LIBRAS como língua de fato, ou seja, tem sistema linguístico, com estrutura gramatical própria e é capaz de transmitir ideias ${ }^{5}$. Em uma pesquisa realizada em 2012 em países desenvolvidos, os autores ${ }^{4}$ mostram que por volta de $80 \%$ das crianças surdas já estão implantadas. Mostram também que os prejuízos que essas crianças têm não se caracterizam apenas pela falta de sucesso com o implante coclear, mas também pela falta de contato 
com a língua de sinais. Segundo essa pesquisa, foi possível demonstrar que a Língua de Sinais é um idioma humano adquirido e utilizado da mesma forma como línguas faladas, com todas as propriedades gramaticais necessárias.

Em nosso trabalho, a LIBRAS entrou como uma alternativa já que as crianças estavam demorando a falar e demorando a desenvolver a linguagem como um todo. Uma mãe relatou ter optado por LIBRAS, pois não queria o filho crescendo apenas com gestos caseiros.

Ao serem questionados sobre a introdução de LIBRAS, quatro familiares relataram que o processo de aprendizagem da língua foi natural e benéfico para as crianças. Uma das mães relatou resistência no início, porém, foi observando avanços na comunicação da filha e aceitou que a mesma adquirisse a língua de sinais. Assim, três familiares disseram que a principal forma de comunicação é por meio da língua de sinais e dois familiares disseram que as crianças se comunicam tanto por língua portuguesa quanto por língua de sinais, de forma que quando a criança não sabe oralizar determinado léxico utiliza sinal. Segue relatos dos familiares quando questionados sobre a introdução da LIBRAS:

"Ah, bem melhor. Porque a fono la de São Paulo, a que ligou o aparelho, ela falou que ele precisava fazer a Libras porque ela queria se comunicar com ele e ela não conseguia. Porque o dele era caseiro, os sinais eram caseiros. Porque onde a gente morava não tinha Libras, ele não tinha.. ele não tinha fono la. Não tinha grupo igual tem aqui. Só ficava na APAE, desde pequenininho sempre ficava na APAE. Aí, eu vim pra cá pra fazer uma cirurgia e vi que aqui pra cá tinha escola, tudo. Daí, ele começou a fazer Libras pra cá porque pra lá não tem ainda." (Sujeito 5)

"Olha, se eu soubesse tinha introduzido a Libras quando ele fez o implante eu tinha introduzido junto. Porque eu acho que se tivesse introduzido junto ele já tava falando, falando e entendendo mais rápido. Fazendo tipo, só oralizando dificultou pra ele. Agora que a gente foi perceber isso. Mas se tivesse colocado os dois junto, tipo o sinal com a palavra, é melhor pra ele. Porque se você fizer 'bola' (com sinal) aí se fazer assim ele já fala. E se eu não fizer ele fica... Entao, ele sabendo o sinal ele fala, ele soletra." (Sujeito 1)

"Ah, eu percebo, viu? Muito... agora da pra entender melhor as coisas que ele fala, que ele quer, entendeu? Porque eu sei pouco também mas da pra conversar com ele. Então eu entendo melhor ele. Da pra gente comunicar muito melhor." (Sujeito 3)

É importante esclarecer que a língua de sinais deu às crianças a oportunidade de desenvolver a linguagem em tempo menor que acontecerá com a língua oral. Ou seja, a partir do momento em que as habilidades para a comunicação foram adquiridas, as crianças se viram prontas para o aprendizado de mundo. Como já dito nesse estudo, é de extrema importância respeitar os cinco primeiros anos de vida da criança, pois é onde se encontra a maior plasticidade cerebral ${ }^{4}$.

\section{Expectativas em relação ao futuro da criança}

Em relação às expectativas sobre o futuro das crianças, os cinco familiares relataram expectativas positivas, como 0 desejo que os filhos tenham oportunidades de estudo, tenham sucesso na carreira profissional e que sejam independentes.

Um estudo realizado em uma instituição pública ${ }^{8}$ revela que quando uma criança surda nasce em uma família ouvinte já são esperadas as expectativas em relação à língua que a criança irá usar para se comunicar. Geralmente as famílias esperam que em uma educação bilíngue as crianças usem a língua de sinais para se comunicar com os surdos e a língua Portuguesa na modalidade oral para se comunicar com ouvintes. Os familiares da pesquisa descreveram as respectivas expectativas de forma mais geral e sem citar diretamente o que ainda esperam do implante coclear (melhora da fala, por exemplo).

"Nossa, eu quero que ele seja... não importa se por fala ou se através de Libras eu quero que ele, sabe, que ele seja independente, quero que ele estude, entendeu? Quero que ele seja alguém na vida. Independente se ele falar ou não." (Sujeito 3) 
"Que quero que ele seja livre porque até hoje, assim, se eu to dentro de casa eu quero que ele fique dentro de casa. Pra eu ver ele, pra eu saber o que ele ta fazendo. Quando ele ta sem aparelho. Agora, quando ele ta com aparelho eu deixo ele brincar na rua, ele vai na pracinha que é do lado de casa, ele vai no parquinho, ele brinca, normal, anda de bicicleta e eu quero que ele seja livre. Eu não quero que ele fique sufocado igual ele fica... agora que quebrou o aparelho eu não confio muito de deixar ele na rua porque eu tenho medo de vir um carro e ele não escutar, né? E é a única coisa que eu quero que ele seja livre, independente que ele estude. Igual ele fala que ele vai trabalhar. Ele quer dinheiro. Apesar que ele recebe, né? Temo $B P C$, ai ele fala que não, que quer trabalhar igual o pai dele." (Sujeito 5)

Em outro estudo realizado com pais de crianças que usam implante coclear, os resultados obtidos com o implante coclear estavam de acordo com as expectativas da maioria deles. Os autores concluíram que as informações dadas em relação ao implante coclear contribuíram para expectativas mais realistas ${ }^{17}$.

As expectativas dos familiares podem ser resumidas em buscar qualidade de vida para os filhos. Um estudo que aplicou o questionário "Children with Cochlear Implants: Parent's Perspectives" (com tradução e adaptação cultural para Português Brasileiro) sobre qualidade de vida de crianças usuárias de implante coclear, obteve como resultado a melhoria que esse dispositivo proporciona na vida das crianças. Os pais mostraram maior satisfação em relação à autoconfiança da criança, nas relações sociais, bem-estar e felicidade, funcionamento geral e comunicação ${ }^{18}$.

\section{Considerações Finais}

Tem-se o implante coclear como um dispositivo ainda pouco conhecido no Brasil, com poucas cirurgias realizadas e como alternativa para os indivíduos com deficiência auditiva de grau severo e profundo. Nesse estudo é possível encontrar limitações já que o numero de sujeitos é reduzido, a instituição em que o trabalho foi realizado é conhecida como instituição bilíngue e, assim, os indivíduos com implante coclear não são encaminhados, pois, espera-se que a reabilitação seja oralista. É necessário que haja mais estudos na área do implante coclear para melhor compreensão do processo de reabilitação auditiva e como obter melhores resultados na aquisição da língua portuguesa de forma que o indivíduo participe de forma efetiva na sociedade. Isso porque o implante coclear por si só não traz pleno sucesso na habilitação auditiva, sendo que outros fatores precisam ser levados em conta como: etiologia da surdez, tempo de privação sensorial auditiva, idade da criança, acesso à terapia interdisciplinar especializada, etc. São necessárias também novas pesquisas nas áreas que incluam o implante coclear e a aquisição de LIBRAS como primeira língua para obtermos possíveis soluções para o desenvolvimento da linguagem das crianças.

Como os familiares deste estudo demonstraram, é importante refletir sobre ter a língua de sinais (língua visuomotora) como primeira língua das crianças que nasceram surdas ou perderam a audição nos primeiros anos de vida para que adquiram conhecimento de mundo e conceitos.

Conclui-se que a escolha pelo implante coclear foi algo que os pais acreditaram ter valido a pena e que acaba se unindo à Língua Brasileira de Sinais para que a criança desenvolva a linguagem de forma mais efetiva. Em relação ao diagnóstico, os familiares relataram sentimentos negativos; indicaram que o diagnóstico foi tardio; estão satisfeitos com a escolha pelo implante coclear; o processo de aprendizagem da língua foi natural e benéfico e relataram expectativas positivas sobre o futuro das crianças.

\section{Referências}

1. Pinto ESM. Análises dos procedimentos de seleção de crianças para o implante coclear [tese de doutorado]. Campinas: Universidade Estadual de Campinas; 2007.

2. Bento RF, Neto RB, Castilho AM, Gómez VG, Giorgi SB, Guedes MC. Resultados auditivos com o implante coclear multicanal em pacientes submetidos a cirurgia no Hospital das Clínicas da Faculdade de Medicina da Universidade de São Paulo. Rev Bras Otorrinolaringol, 2004 set/out; 70 (5): 632-637.

3. Gomez MVSG, Guedes MC, Santanna SBG, Peralta CGO, Tsuji RK, Castilho AM, Neto RVB, Bento RF. Critérios de seleção e avaliação médica e audiológica dos candidatos ao implante coclear: protocolo HC-FMUSP. Int Arch Otorhinolaryngol. 2004 out/dez; 8 (4): 295-317. 
4. Humphries T, Kushalnagar P, Mathur G, Napoli DJ, Padden C, Rathmann C, Smith SR. Language acquisition for deaf children: Reducing the harms of zero tolerance to the use of alternative approaches. Harm Reduct J. 2012 abr; 9 (16): 2-9. 5. BRASIL. Lei No 10.436, de 24 de abril de 2002. Dispõe sobre a Língua Brasileira de Sinais - Libras e dá outras providências. Presidência da República, Subchefia para Assuntos Jurídicos. 2002. Disponível em: http://www.planalto. gov.br/ccivil_03/leis/2002/L10436.htm

6. Perlin GTT. Identidades surdas. In: Carlos Skliar. A surdez: um olhar sobre as diferenças. Porto Alegre: Mediação; 2010. p. 51-73.

7. Dias $A B$, Lourenço EA. Implante coclear precoce e tardio: desenvolvimento da audição e da linguagem com e sem o apoio da Língua Brasileira de Sinais [apresentação no 310 Encontro Internacional de Audiologia; 2016 mai; São Paulo, Brasil]. 8. Silva ABP, Zanolli ML, Pereira MCC. Mães Ouvintes com Filhos Surdos: Concepção de Surdez e Escolha da Modalidade de Linguagem. Psicol teor pesqui. 200723 (3): 279-286.

9. Minayo MCS, Gomes SFDR. Pesquisa Social: teoria, método e criatividade. 29ed. Petrópolis: Vozes; 2010.

10. Minayo MCS. O desafio do conhecimento: pesquisa qualitativa em saúde. $4^{\mathrm{a}}$ ed. São Paulo: Hucitec; 2006.

11. Bardin L. Análise de conteúdo. 4. ed. Lisboa: Editora 70; 2004.

12. Bardin L. Análise de conteúdo. São Paulo: Edições 70; 2011.

13. Buscaglia L. Os deficientes e seus pais: um desafio ao aconselhamento. Rio de Janeiro: Record; 1993.

14. Vieira SS, Bevilacqua MC, Ferreira NMLA, Dupas G. Descoberta da deficiência auditiva pela família: vendo o futuro idealizado desmoronar. Acta paul enferm. 2012 25(2): 82-8.

15. Nicholas JG, Geers AE. Personal, social, and Family adjustment in school-aged children with a cochlear implant. Ear Hear. 2003 24(1): 69-81.

16. Yamada MO, Valle ERM. Vivência de mães na trajetória de seus filhos com implante coclear: fatores afetivos e emocionais. $2^{\mathrm{a} e d .}$ Ribeirão Preto: Book Toy; 2014.

17. Sach TH, Whynes DK. Pediatric cochlear implantation: the views of parents. Int J Audiol. 2005 44(7): 400-407.

18. Tavares TF, Lopes DB, Bento RF, Andrade CRF. Crianças com implante coclear: habilidades comunicativas e qualidade de vida. Braz J Otorhinolaryngol. 201278 (1): 15-25. Disponível em: http://www.scielo.br/pdf/bjorl/v78n1/v78n1a03.pdf.

\section{Lauriene Franchi Dionísio}

Endereço para correspondência - Ana Jacinta de Andrade Couto, $n^{\circ} 732$,

Bairro: Parque Industrial, CEP: 13031- 400, Campinas, SP, Brasil.

E-mail: fono.lauriene@gmail.com

Lattes: http://lattes.cnpq.br/0762614471904793

Maria Cecília Marconi Pinheiro Lima - ceclima@fcm.unicamp.br

Enviado em 06 de abril de 2016. Aceito em 30 de dezembro de 2016. 